\title{
RELAÇÃO ENTRE ORIENTAÇÃO EMPREENDEDORA, GESTÃO DE CUSTOS E DESEMPENHO ORGANIZACIONAL NO RAMO HOTELEIRO
}

Suzete Antonieta Lizote ${ }^{1}$

Sayonara De Fátima Teston ${ }^{2}$

Patrick Zawadzki

Gabriel Gaiato*1

${ }^{1}$ Universidade do Vale do Itajaí

${ }^{2}$ Universidade do Oeste de Santa Catarina (UNOESC) 


\section{RELAÇÃO ENTRE ORIENTAÇÃO EMPREENDEDORA, GESTÃO DE CUSTOS E DESEMPENHO ORGANIZACIONAL NO RAMO HOTELEIRO}

Resumo: A presente pesquisa tem como objetivo avaliar a relação entre orientação empreendedora e desempenho organizacional considerando como os hotéis realizam a gestão de custos. Os dados obtiveram-se junto à hotelaria brasileira da região sul por meio de uma survey com questionário, que levantava a percepção dos gestores. Os custos foram trabalhados segundo o método utilizado para estimá-los, o critério de precificação da diária, os principais custos de hospedagem e em relação a sua utilidade. Ao total recolheram-se 112 questionários de hotéis localizados em 16 cidades da Região Sul do Brasil. Os dados obtidos analisaram-se estatisticamente empregando a Anova e por meio da análise de correlação de Spearman. Os resultados deste estudo evidenciaram que os hotéis que adotam o método de custeio baseado em atividades e formam o preço considerando os valores de mercado são os que possuem respectivamente maior orientação empreendedora e desempenho.

Palavras-chave: Orientação empreendedora. Custos. Desempenho. Hotéis.

\section{Introdução}

A Orientação Empreendedora (OE) pode ser considerada como um constructo da gestão estratégica das empresas. É um conceito que tem emergido no contexto organizacional com a finalidade de investigar o espírito empreendedor nas empresas e como isto influencia nos processos estratégicos e no desempenho (Rauch et al., 2009). De acordo com Martens e Freitas (2010) a OE emerge da oportunidade de novos negócios que podem ser empreendidos com sucesso de forma ponderada, envolvendo as intenções e ações principais em um processo dinâmico de criação de novos negócios.

Destaca-se também que entre os temas mais estudados no âmbito da administração estratégica encontra-se o desempenho organizacional e que na sua análise têm sido utilizadas diversas aproximações. Dentre elas, uma que vem ganhando importância é a orientação empreendedora que as firmas manifestam, pois se refere aos processos estratégicos que possibilitam às organizações dispor de uma base para definir sua tomada de decisões. Portanto, nos debates sobre estratégia, teoria das organizações e empreendedorismo, cada vez mais pesquisas mostram que o desempenho organizacional e a sustentabilidade dos negócios são influenciados positivamente pela capacidade de empreender e inovar (Covin \& Slevin, 1991; Rauch, et al. 2009; Martens et al., 2016).

A gestão de custos é uma importante ferramenta para a tomada de decisões nas empresas. Os efeitos de suas decisões serão percebidos tanto no presente quanto em longo prazo e ainda estarão resguardadas na escolha da alternativa que proporciona maior vantagem competitiva. Tal afirmação é amparada por Bruni e Famá (2004, p. 237) "a ênfase da análise de custos deve estar baseada nas decisões tomadas e seus efeitos subsequentes". Nota-se, que é de grande importância a geração das informações, assim como o seu uso eficaz e o fornecimento de 
subsídios durante todo o processo da gestão dos negócios. O melhor preço poderá decidir o sucesso ou o fracasso do empreendimento turístico, pois é por meio dele irá atrair e fidelizar os clientes, e é por meio do preço que o estabelecimento saberá se está obtendo lucros ou amargando prejuízos (Leitão \& Silva, 2006). No ramo hoteleiro, Castillo e Quintero (2013) salientam que a maximização de receitas favorece o gerenciamento eficaz entre administração de demanda e o faturamento. Segundo os autores, isso ocorre porque envolve a seleção e o uso de ferramentas de marketing para trazer ao meio de hospedagem o marketing mix desejado, fundamental, para analisar o mercado, a concorrência e desenvolver preços e tarifas para cada segmento.

A gestão de custos permite uma melhor visualização dos gastos, ao identificar as atividades envolvidas na prestação de serviço, exercendo uma ação eficaz de controle de custos. Neste cenário, Hansen e Mowen (2001, p. 31) relatam que "o aumento da concorrência tornou aos gestores nesse setor mais conscientes da necessidade de usar informações contábeis para o planejamento, o controle e as tomadas de decisão".

Com um incremento constante da concorrência, devido à internacionalização dos mercados, o ambiente de negócios na atualidade tem induzido à adoção de ações empreendedoras na definição das estratégias empresariais, tornando-se um fator essencial para o sucesso das firmas (Dess et al., 1997). Ganha destaque, então, atuar proativamente na identificação de oportunidades e ameaças, realizar inovações, seja em produtos ou serviços, e assumir os riscos implícitos, com a finalidade desenvolver o gerenciamento do crescimento. Em conjunto com essas características básicas, conforme as circunstâncias e o tipo de organização, é possível identificar outras práticas e atividades, incluindo ações autônomas dos departamentos da empresa ou atitudes agressivas em relação aos concorrentes (Lumpkin \& Dess, 1996, Hughes \& Morgan, 2007).

Estudos sobre orientação empreendedora tem crescido ao longo dos anos (Covin \& Wales, 2018), entretanto, um aspecto que não tem sido considerado com a mesma ênfase nas pesquisas é como os métodos de custeio e os mecanismos de precificação se relacionam com as estratégias empreendedoras das entidades. Sem dúvidas, para competir no contexto ambiental presente continua a ser determinante um gerenciamento eficiente dos custos. Mas, ao assumir uma orientação empreendedora, na análise do planejamento e da definição das estratégias devem-se incluir as ações proativas e seus riscos implícitos (Lumpkin, Moss, Gras, Kato, \& Amezcua (2013).

Diante deste contexto surge a pergunta que norteia a presente pesquisa: Que relações se verificam entre a orientação empreendedora que dispõem os hotéis e seu desempenho organizacional levando em conta o gerenciamento de custos que efetuam? Para respondê-la definiu-se como objetivo geral, avaliar a relação entre orientação empreendedora e desempenho considerando como os hotéis realizam a gestão de custos.

Com o presente estudo buscou-se obter novas evidências empíricas sobre as relações entre os construtos mencionados. Sua consecução, além de original para as organizações foco da pesquisa ao trazer como um dos determinantes o gerenciamento dos custos, possui relevância prática para a melhoria do funcionamento dos hotéis. Por outro lado, as proposições de articulações teóricas, ainda pouco trabalhadas em estudos empíricos da realidade brasileira justificam o interesse acadêmico. 
Este artigo está estruturado em cinco seções, iniciando por esta introdução, na segunda, contempla-se o marco teórico do estudo. A seção três apresenta o material e métodos, e na seção seguinte são apresentados e discutidos os resultados. Na última seção expõem-se as considerações finais e se apresentam sugestões para novos estudos, disponibilizando-se a seguir as referências bibliográficas citadas.

\section{Referencial Teórico}

Nesta seção apresenta-se o marco teórico definido como necessário à compreensão da abordagem adotada.

\subsection{Orientação Empreendedora}

A orientação empreendedora (OE) surgiu como um conceito importante para pesquisar o espírito empreendedor nas organizações, bem como sua influência nos processos estratégicos e de desempenho (Rauch et al., 2009). Inicialmente foi interpretada como uma qualidade particular do proprietário ou gestor, ou seja, alguém que, por meio da implementação de ações corporativas, desafiava as incertezas ambientais. Entretanto, para Miller (1983) a orientação empreendedora devia ser interpretada como uma característica das empresas, indo além do desempenho de um único indivíduo.

Os estudos sobre a OE iniciaram com Miller (1983). Sua proposição inicial contempla três dimensões. (1) inovatividade: que reflete a tendência da organização em apoiar novas ideias, experimentos, novidades e processos criativos que possam resultar em novos processos, produtos ou serviços (Lumpkin \& Dess, 1996); (2) proatividade: que se relaciona com uma perspectiva de futuro, por meio da qual as empresas procuram antecipar oportunidades para desenvolver e introduzir novos serviços ou produtos no mercado, visando obter vantagem competitiva (Miller, 1983); e, (3) assunção de riscos: uma dimensão que, segundo Venkatraman (1989), reflete o grau de risco em decisões de alocação de recursos, assim como na escolha de produtos e mercados.

A partir do estudo pioneiro de Miller, foram Lumpkin e Dess (1996) os que propuseram mais duas dimensões para a OE: agressividade e autonomia. A primeira se manifesta quando se busca alcançar, a qualquer custo, uma maior participação de mercado (Venkatraman, 1989) e também se revela como uma resposta a ameaças no ambiente de negócios (Lumpkin \& Dess, 2001) Já a autonomia verifica-se quando o empreendedor deve tomar decisões pelo uso de recursos, no estabelecimento de objetivos, na escolha de estratégias de ação ou na procura de oportunidades relevantes, dentre outras ações (Lumpkin, Cogliser \& Schneider, 2009).

Lumpkin e Dess (1996) identificaram que coexistia uma tendência superficial de assumir a orientação empreendedora como algo essencial e positivo para o desempenho organizacional. Esses autores comentaram que o fato de haver diferenças de empreendedorismo entre uma organização e outra pode ser decorrente da combinação de vários fatores: individuais, organizacionais e ambientais. Esta última variável poderia moderar ou mediar à relação da $\mathrm{OE}$ com o desempenho. Contudo, independente do como afete o ambiente, diversas pesquisas têm demonstrado uma relação positiva entre esses constructos (Gupta \& Dutta, 2016; Kraus et al. 2017). 
Segundo os estudos de Fernandes e Santos (2008), a orientação empreendedora exerce elevado impacto na performance empresarial; seus efeitos são maiores do que na orientação para o mercado, os quais influenciam mais o sucesso das inovações. Juntamente com orientação para o mercado se complementam, e seus efeitos trazem resultados as ações empresariais. Para Wiklund \& Shepherd, (2003); Martens \& Freitas, (2010), a OE é considerada benéfica para as organizações, porque positivamente associada ao crescimento, tem impacto positivo nas medidas de performance financeira podendo cooperar com a aptidão de descobrir novas oportunidades, facilitando a distinção e a criação de vantagem competitiva.

Nas pesquisas nacionais, Lazzarotti et al (2015) analisaram a OE em suas dimensões comportamento inovador, assunção de riscos, proatividade, autonomia, agressividade competitiva e redes de relações - e sua associação com o desempenho das empresas graduadas das incubadoras brasileiras. Os achados do estudo evidenciaram que dimensão que contribuiu mais fortemente para a existência da $\mathrm{OE}$ foi a autonomia, e que as redes de relações, dimensão não mencionada até então pelos estudos anteriores, colaboraram de forma análoga às demais dimensões para a composição da OE.

Analisar a manifestação da Orientação Empreendedora nas ações de uma organização sem fins lucrativos à luz do modelo de Morris, Webb e Franklin (2011) foi o estudo desenvolvido por Lacerda, Belfort e Martens (2015). Os resultados permitiram identificar a manifestação das dimensões inovatividade, proatividade e assunção de riscos nas ações realizadas pela organização diante das suas necessidades ou busca pelas oportunidades (motivação, processos e resultados).

Oro e Lavarda (2017) por sua vez, estudaram como ocorre a interação entre estratégia de negócios e desempenho organizacional nas empresas familiares. Os resultados indicam que a orientação empreendedora e a influência da família desempenham um papel importante para a realização de ajuste estrutural e estratégico e, por sua vez, para a realização do desempenho organizacional.

Destaca-se também a pesquisa de Tonial e Rossetto (2018) que objetivou analisar práticas empreendedoras que caracterizam a Orientação Empreendedora Internacional (OEI) em empresas vinícolas internacionalizadas do Sul do Brasil. Os achados evidenciaram maior ocorrência das práticas empreendedoras nas dimensões inovatividade internacional e proatividade internacional. Nas dimensões assunção ao risco internacional, agressividade competitiva e autonomia Internacional, as práticas foram identificadas com menor ocorrência. O estudo de Silva e Lizote (2019) buscou analisar as associações entre autoeficácia empreendedora e orientação empreendedora em pequenas empresas de moda íntima de Santa Catarina. Os resultados evidenciaram que a assunção de risco foi a dimensão da orientação empreendedora que apresentou mais relações significantes. Penz et al (2019), por sua vez, pesquisaram o grau de Orientação Empreendedora $(\mathrm{OE})$ existente nos brasileiros que optaram por investir seus esforços e iniciaram novos empreendimentos nos EUA. Os dados da pesquisa evidenciaram que a amostra estudada possui as características propostas por Miller (1983) nas seguintes proporções: $56 \%$ para inovação, $78 \%$ para proatividade e $73 \%$ para tomada de risco. 


\subsection{Gestão de Custos}

A gestão de custos vem ganhando cada vez mais importância nas empresas devido a grande concorrência existente na maior parte dos mercados na atualidade. Isto torna difícil para a organização definir seus preços de venda e, portanto, segue o preço definido pelo "mercado". Assim, a gestão de custos possibilita aos administradores ter uma visão mais realista e um meio de melhor gerenciá-los, tornando possível concorrer em mercados altamente competitivos através da sua redução (Koliver, 2009). Algumas ferramentas são imprescindíveis para essa finalidade, incluindo os métodos de custeio, os quais permitem a correta alocação dos custos incorridos pela empresa.

No caso de serviços, torna-se difícil mensurar a sua importância, como também de fazer atribuição de valores. Para Perez Jr., Oliveira e Costa (2005, p. 338), "a prestação de serviços, quase sempre envolve aspectos intangíveis, diferentemente da produção física de determinado produto material ou tangível". Essas informações são essenciais para o planejamento de ações futuras, além de comunicar aos gestores os dados de origem econômica e financeira da instituição. Neste cenário, Hansen e Mowen (2001, p. 34) contribuem relatando que "a mensuração e os relatórios de custos da qualidade são características-chaves dos sistemas de gestão de custos tanto para setores de manufatura quanto de serviços". Com a mensuração, os administradores podem efetuar o controle dos custos, visando determinar a rentabilidade da empresa. O controle, assim como o planejamento em qualquer instituição, é indispensável. Lunkes $(2009$, p. 346) enfatiza que "Os hotéis que entendem a necessidade de criar valor têm como grande desafio encontrar formas de operacionalizar os novos métodos de gestão, como os relacionados a custos"

Hansen e Mowen (2001, p. 123) descrevem que "os gestores devem ser capazes de rastrear os custos dos serviços prestados tão precisamente quanto devem rastrear os custos dos produtos manufaturados". As instituições que priorizarem o tempo, a qualidade e a eficiência na produção de bens ou na execução de seus serviços, estarão agregando valor ao produto e, desta forma, alcançarão a vantagem competitiva para com seus concorrentes. Consoante a isso, eles reforçam que "para assegurar e manter uma vantagem competitiva, os gestores enfatizam o tempo, a qualidade e a eficiência." (Hansen \& Mowen 2001, p. 31).

A formação de preços foi uma das primeiras ferramentas criadas pela teoria dos custos, demonstrando seu papel fundamental, já que antes da sua existência era impossível calcular o custo de um produto ou serviço, elemento considerado essencial para formar o preço ou valor de venda de um produto. Atualmente a realidade das empresas quanto à formação de preços modificou-se, já que o mercado globalizado força também às empresas a adaptar seus preços ao que é praticado pelos seus concorrentes.

Ainda, existe outra corrente que acredita ser o preço uma função do valor percebido pelo consumidor ao invés de ser relacionado ao custo de produção (Beulke \& Bertó, 2001). De forma complementar Viana Filho, Gomes e Souza (2011) descrevem que os preços de venda definidos pelas entidades sugerem a estratégia e a finalidade desejada pela mesma. Dentre as que incluem: sustentar sua posição no mercado, aumentar seu market share em determinado segmento do mercado, tornarem-se competitivas ou, tentarem sobreviver. Diante disso, a consciência quanto ao custo de se realizar um serviço não perdeu valor, e sim se alterou a visão a respeito do mesmo. $\mathrm{Na}$ atual conjuntura os custos passam "a constituir um piso do preço e elemento 
absolutamente decisivo para a avaliação do desempenho de produtos, mercadorias e serviços" (Beulke \& Bertó, 2001, p. 21).

Bruni e Fama (2004, p. 321) citam alguns dos principais objetivos quando da utilização das metodologias para formação de preços, sendo eles: proporcionar o maior lucro possível no longo prazo; maximizar a participação de mercado de forma lucrativa; maximizar a capacidade produtiva de forma a reduzir a ociosidade e as despesas operacionais; e, maximizar a rentabilidade do capital empregado para perpetuar os negócios de forma autossustentável.

No âmbito nacional destacam-se os estudos de Lunkes (2009) que investigou sobre a existência de informações de custos em empresas hoteleiras da cidade de Florianópolis (SC). Os resultados revelam que $40 \%$ dos hotéis utilizam algum sistema de custeio.

O estudo de Santos e Flores (2017) analisou as estratégias de formação de preços nos meios de hospedagem em São Luís/Maranhão/Brasil. A pesquisa aponta são utilizadas as ferramentas e estratégias de gestão de preços recomendados pela legislação e outras de apoio para gestão dos preços e que há um esforço da gestão dos hotéis para profissionalizar os métodos de cálculo da diária, utilizando técnicas que lhes deem maior segurança na decisão e formação de preços, abandonando os métodos informais ou empíricos, sem abandonar a pesquisa de mercado.

Leite, Lamase Nobrega (2019) buscaram investigar a correlação entre as práticas de Gestão Ambiental e a precificação dos serviços de hospedagem; e de qual forma as práticas ambientais são divulgadas como estratégia competitiva no mercado. Os resultados apontaram que o sistema de gestão ambiental nesses empreendimentos está associado à redução dos custos operacionais, que não há uma correlação direta das práticas ambientais com a definição dos preços praticados, e que a divulgação de tais práticas, ainda que reconhecidamente necessária, não é trabalhada como uma estratégia competitiva no mercado local.

Verificar os fatores determinantes das práticas de gestão de custos utilizadas no processo decisório de empresas da região Oeste catarinense foi a pesquisa desenvolvida por Zanin, Dal Magro e Mazzioni (2019). Os resultados indicaram que o método de custeio variável é o mais utilizado pelas empresas da amostra. $\mathrm{O}$ ramo de atividade, forma de tributação e faturamento anual mostraram-se fatores decisivos para a utilização das ferramentas de custos de produção e orçamento.

\subsection{Desempenho Organizacional}

A avaliação de desempenho serve para controlar uma estratégia definida pela organização, confrontando seu resultado com os objetivos estabelecidos. Nesta ótica Neely et al. (2005) a veem como um processo de quantificação da eficiência e efetividade das ações empresariais. Para Igarashi et al. (2008) é mediante a análise do desempenho que as organizações podem medir a sua capacidade de sobrevivência e continuidade, face às exigências do ambiente interno e externo em que estejam inseridas. $\mathrm{O}$ crescimento do interesse pelas medidas de desempenho organizacional deve-se às importantes mudanças tanto no ambiente empresarial quanto nas estratégias adotadas.

A avaliação do desempenho é considerada fundamental para a gestão eficaz e eficiente de qualquer organização (Melnyk et al., 2014). Constitui-se como o processo destinado a mensurar a eficácia e a eficiência de determinada ação, podendo também significar a gestão dos 
stakeholders ou suas relações organizacionais (Neely et al., 1995, Halachmi, 2005; Davenport \& Harris, 2007).

No que tange a sua mensuração, Gunasekaran e Kobu (2007) consideram um grande desafio para os administradores o desenvolvimento de medidas apropriadas para a tomada de decisões que contribuam para o alcance da competitividade. O desempenho pode ser mensurado através de duas perspectivas: primeiramente como conceito subjetivo, o qual está relacionado ao desempenho das organizações segundo a sua própria expectativa ou relativamente à concorrência (Pelham \&Wilson, 1996). A segunda opção é analisá-lo pelo método objetivo, baseado em medidas absolutas de desempenho (Chakravarthy, 1996).

Para dar suporte às decisões estratégicas da organização sua mensuração, segundo Bortoluzzi et al. (2010), deve considerar alguns elementos importantes, quais sejam: levar em consideração as particularidades de cada organização; considerar indicadores financeiros e não financeiros, ou seja, os aspectos tangíveis e intangíveis; ligar os objetivos estratégicos com os objetivos operacionais; e, construir um processo de comunicação que permita a todos os níveis organizacionais identificar de forma clara e holística os objetivos que a organização está idealizando. Neste sentido, Pires et al. (2019) destacam que os indicadores são medidas de desempenho que quantificam o que está acontecendo e permitem a comparação com o padrão de desempenho esperado.

Entretanto, a validade de usar indicadores subjetivos de desempenho tem sido demonstrada como alternativa viável para o caso de inexistência de dados secundários confiáveis (Perin \& Sampaio, 1999) o bem a impossibilidade de obtê-los. Conforme comenta Hoque (2005) os motivos pelos quais geralmente são escolhidas as medidas subjetivas ocorrem porque uma parcela significativa de pequenas empresas não possui ou bem dispõem de poucas informações objetivas, tornando quase que impossível conferi-las com precisão.

Neste estudo, escolheu-se utilizar medidas subjetivas de desempenho, trabalhando com a percepção dos gestores dos hotéis. Esta decisão se baseia no fato de que este constructo constitui a variável dependente no modelo e sua mensuração, como um valor em relação aos concorrentes mais próximos, é apropriada para estimar as relações que com ele tem a orientação empreendedora e a gestão de custos.

\section{Metodologia}

Diante dos critérios adotados, a abordagem do problema foi quantitativa. A avaliação quantitativa compreende organizar, sumarizar, caracterizar e interpretar os dados numéricos (Martins \& Theóphilo, 2007). Em relação ao objetivo, classifica-se como um estudo descritivo. Para Vergara (1998) os objetivos da pesquisa descritiva se referem à obtenção de informações sobre um fenômeno ou sobre determinada população e à descrição de suas características. No que tange aos procedimentos técnicos, foi do tipo levantamento, que tem como objetivo contribuir para o conhecimento de uma área particular de interesse através da coleta de dados sobre indivíduos ou sobre o ambiente destes (Trez \& Matos, 2006).

O material para o estudo foi obtido por meio de um questionário de autopreenchimento que foi respondido pelos gestores de hotéis de 16 cidades da Região Sul do Brasil. Escolheram-se hotéis das categorias econômico, turístico e superior, que na antiga classificação brasileira correspondiam a dois, três e quatro estrelas respectivamente. Dos 200 questionários enviados 
via correio eletrônico retornaram 112 representando taxa de $56 \%$.

$\mathrm{O}$ instrumento estava organizado em cinco blocos. No primeiro se recolheram informações do respondente e sobre a organização. No segundo se dispuseram quatro questões referidas a custos. Perguntava-se sobre o método utilizado para avalia-los, o critério adotado para estabelecer os preços, os principais custos do hotel e a respeito da utilidade que tinham as informações sobre custos.

Com a finalidade de levantar os dados sobre a orientação empreendedora que o hotel manifestava empregou-se, no terceiro bloco, uma escala Likert de concordância com sete pontos, indo desde discordo totalmente (1) até concordo plenamente (7). Trabalhou-se a partir da proposta de Covin e Slevin (1989) que, com base no trabalho de Miller (1983), criaram um instrumento para obter dados sobre proatividade, assunção de riscos e inovatividade. Para as duas primeiras dimensões se usaram cinco asseverações e para a última seis.

No quarto bloco, usando também uma escala de concordância de sete pontos, se dispuseram oito asseverações sobre práticas de custos. Nelas tratavam-se os seguintes assuntos: 1) realização do planejamento estratégico e orçamentário com acompanhamento mensal; 2) fornecimento de informações da contabilidade de custos sobre a margem bruta; 3) fornecimento de informações da contabilidade de custos sobre a margem de contribuição; 4) planejamento de atividades com orçamento detalhado; 5) acompanhamento dos custos efetivamente incorridos e comparação com o orçado; 6) avaliação da contribuição dos clientes para o resultado financeiro; 7) uso das informações da contabilidade de custos para o planejamento, gestão e controle; e, 8) uso associado das informações de custos com a contabilidade de custos para o planejamento, gestão e controle.

Por fim, no quinto bloco se levantaram dados sobre o desempenho, mensurado de modo subjetivo, em relação ao concorrente mais próximo. Utilizou-se, da mesma forma que nos dois blocos anteriores, uma escala de concordância de sete pontos. Nela o respondente devia assinalar se o hotel que gerencia tinha uma melhor performance nos seguintes aspectos: 1) no lucro líquido; 2) nas vendas totais; 3) na realização dos resultados financeiros; 4) no cumprimento das metas de pessoal e emprego; 5) no cumprimento das metas de satisfação do cliente; 6) na retenção de clientes; e, 7) no desempenho geral.

Os dados colhidos foram organizados numa planilha eletrônica Excel® sendo feitos os préprocessamentos sugeridos em Hair Jr. et al. (2009). Inicialmente se quantificaram 38 dados omissos, mas como sua distribuição não se associava a nenhum padrão os dados faltantes foram preenchidos com o valor da mediana do item em que se registrou a omissão. Logo, avaliaramse os outliers usando a função gráfica Box-Plot do software Statistica ${ }^{\circledR}$, com a que foram reconhecidos 49 que se optou por manter ao não se reconhecer padrão na sua distribuição.

A seguir foram calculadas a média, desvio padrão, assimetria, curtose e coeficiente de variação $(\mathrm{CV})$. Possibilitando-se assim fazer a análise descritiva das variáveis. Por outra parte, segundo Finney e DiStefano (2006) se a assimetria e a curtose não ultrapassarem em módulo os valores de 2 e 7, respectivamente, as distribuições dessas variáveis podem ser consideradas quase normais.

Os dados foram separados por país e importados aos softwares Statistica e SPSS®, com os quais se realizaram análises fatoriais exploratórias para definir os itens que se consideraram para cada dimensão da orientação empreendedora, para as práticas de custos e o desempenho. Colocou-se como restrições que o constructo seja expresso por um único fator extraído da 
matriz de correlações segundo o critério de Kaiser, que a variância a ele associada seja no mínimo 50\% e que as correlações dos itens com o fator sejam maiores do que 0,60 em módulo. Para cada dimensão da OE, as práticas de custo e o desempenho se geraram os escores fatoriais derivados do fator extraído. Com essas novas variáveis se efetuaram as análises de correlação para avaliar se existe associação entre os constructos. Empregou-se o coeficiente de correlação de Spearman devido à falta de normalidade dos dados. Posteriormente, com essas mesmas variáveis de síntese, foram desenvolvidas análises de variância (Anova) usando as respostas às quatro questões de custos como os preditores categóricos. As Anovas realizadas foram sempre univariadas e, portanto, muito robustas frente à presença de não normalidade e heterocedasticidade (Harris, 1975).

\section{Resultados}

Em relação ao tamanho dos hotéis se caracterizaram primeiro pelo número de unidades habitacionais (UH). Deles 30 tinham até 49 UH. Entre 50 e 100 UH foram 71 hotéis. Por fim, teve 11 hotéis com mais do que $100 \mathrm{UH}$. Quanto ao tamanho mensurado pelo número de funcionários se observa que predominam os hotéis que tem entre 10 e 49 empregados, alcançando a quantidade de 58. Com um número entre 50 e 100 funcionários na amostra há 50 empresas hoteleiras e quatro com mais de 100. Dos respondentes 62 tinham o cargo de gerente geral, 32 gerente comercial, 10 gerente operacional e 8 o cargo de coordenador ou supervisor. Já pelo gênero, 73,5\% dos respondentes foram homens e 26,5\% mulheres.

Com relação às variáveis o primeiro tratamento foi fazer uma análise descritiva calculando a média, desvio padrão, assimetria e curtose. Os resultados desses processamentos se exibem na Tabela 1, onde se podem observar os valores obtidos para as três dimensões da orientação empreendedora, as práticas de custo e o desempenho. A menor e a maior média que se observam na tabela foram calculadas para a orientação empreendedora, sendo respectivamente a do item 1 da dimensão inovatividade e do item 2 da proatividade. Quando efetuada uma Anova para comparar todas as médias das dimensões da $\mathrm{OE}$, das práticas de custo e do desempenho, se constata que há diferenças na comparação simultânea e ao realizar o teste de Tukey para número desigual de elementos se confirma que a proatividade tem média $(6,18)$ significativamente maior do que a assunção de riscos $(4,68)$. Ou seja, os hotéis demonstram proatividade e inovatividade, mas não assumem riscos numa medida equivalente. 


\begin{tabular}{l|l|l|l|l|l|l|l|l|l|l|l}
\hline Item & Média & $\begin{array}{l}\text { Desvio } \\
\text { Padrão }\end{array}$ & Assimetria & Curtose & CV & Item & Média & $\begin{array}{l}\text { Desvio } \\
\text { Padrão }\end{array}$ & Assimetria & Curtose & CV \\
\hline PR1 & 6,17 & 0,8567 & $-0,3380$ & $-1,5583$ & 0,1388 & PC1 & 6,30 & 0,8038 & $-0,8939$ & $-0,0182$ & 0,1275 \\
\hline PR2 & 6,69 & 0,5682 & $-1,6884$ & 1,8572 & 0,0849 & PC2 & 5,24 & 1,3658 & $-0,2108$ & $-0,9904$ & 0,2609 \\
\hline PR3 & 6,25 & 0,8252 & $-0,7070$ & $-0,5699$ & 0,1320 & PC3 & 5,31 & 1,4029 & $-0,3913$ & $-1,0320$ & 0,2643 \\
\hline PR4 & 5,71 & 1,2601 & $-0,2197$ & $-1,6299$ & 0,2208 & PC4 & 6,63 & 0,6563 & $-2,0847$ & 5,4409 & 0,0989 \\
\hline PR5 & 6,08 & 0,9225 & $-0,1568$ & $-1,8160$ & 0,1518 & PC5 & 5,84 & 1,0774 & $-0,7468$ & 0,2922 & 0,1846 \\
\hline IN1 & 2,73 & 1,4632 & 0,3909 & $-0,4209$ & 0,5369 & PC6 & 6,23 & 0,7694 & $-0,4211$ & $-1,1962$ & 0,1235 \\
\hline IN2 & 5,27 & 1,2169 & $-0,4742$ & 1,0259 & 0,2307 & PC7 & 5,35 & 1,3433 & $-0,4352$ & $-0,7493$ & 0,2512 \\
\hline IN3 & 5,67 & 1,0203 & $-0,1925$ & $-0,2931$ & 0,1801 & PC8 & 5,25 & 1,3551 & $-0,3287$ & $-0,9147$ & 0,2579 \\
\hline IN4 & 6,34 & 0,7868 & $-0,6783$ & $-1,0598$ & 0,1241 & DO1 & 5,90 & 1,0599 & $-1,0059$ & 0,8249 & 0,1796 \\
\hline IN5 & 6,36 & 0,7333 & $-0,7636$ & $-0,4809$ & 0,1152 & DO2 & 5,92 & 0,9510 & $-1,2552$ & 2,1479 & 0,1607 \\
\hline IN6 & 6,44 & 0,6887 & $-0,8370$ & $-0,5009$ & 0,1069 & DO3 & 5,97 & 0,9064 & 0,0680 & $-1,7876$ & 0,1519 \\
\hline AR1 & 4,79 & 1,8988 & 0,2062 & $-1,8347$ & 0,3965 & DO4 & 5,76 & 0,7728 & 0,1206 & $-0,4114$ & 0,1342 \\
\hline AR2 & 4,87 & 1,8799 & 0,0676 & $-1,7785$ & 0,3862 & DO5 & 6,61 & 0,5374 & $-0,9207$ & $-0,2453$ & 0,0813 \\
\hline AR3 & 5,03 & 1,7599 & $-0,0363$ & $-1,7406$ & 0,3496 & DO6 & 6,02 & 0,8506 & $-0,0469$ & $-1,6197$ & 0,1412 \\
\hline AR4 & 4,12 & 2,1209 & 0,3480 & $-1,3935$ & 0,5151 & DO7 & 5,79 & 1,2115 & $-0,6287$ & $-0,6381$ & 0,2093 \\
\hline AR5 & 4,58 & 2,0019 & 0,1815 & $-1,7133$ & 0,4368 & $*$ & $*$ & $*$ & $*$ & $*$ & $*$ \\
\hline
\end{tabular}

Tabela 1 - Estatísticas descritivas dos indicadores de proatividade (PR), inovatividade (IN) e assunção de risco (AR) da orientação empreendedora, da prática de custos (PC) e do desempenho organizacional (DO).

$\mathrm{Na}$ análise individual das dimensões da orientação empreendedora, para a proatividade se verifica que a maior média foi a da questão 2, que se refere à resposta dos hotéis à ação dos concorrentes. Isso significa que para o setor algo importante é acompanhar as iniciativas que os concorrentes tiverem. Já a menor média se constata para a questão que trata da ação proativa do hotel quando há ambiguidade ou dúvidas nas regras governamentais, levantada no item 4. Ou seja, nesse resultado se reflete que as organizações têm um comportamento pouco proativo diante de incertezas ambientais.

Na dimensão inovatividade o valor médio mais alto foi para a questão que destaca as inovações que assegurem o desenvolvimento de serviços que atendam as expectativas dos clientes (IN6). Por sua vez, a menor média foi para a valorização da pesquisa e desenvolvimento de produtos ou serviços novos a implantar no hotel (IN1). Por fim, as médias da assunção de riscos, como se mostra na Tabela 1, foram as mais baixas entre as três dimensões da orientação empreendedora, o que se corroborou com o resultado da Anova. A média maior $(5,03)$ foi para o item que trata de adotar uma postura arrojada para atingir os objetivos da empresa e a menor $(4,12)$ se teve na questão que se refere a adotar uma postura agressiva em prol de explorar oportunidades potenciais.

Em relação às práticas de custos a maior média $(6,63)$ se obteve para o item PC4, referida ao planejamento das atividades do hotel segundo um orçamento detalhado dos custos. Para o desempenho a média mais alta foi para o item DO5 $(6,61)$ que trata de dar cumprimento às metas de satisfação do cliente. Quando se avalia a relação entre o desvio padrão e a média, isto é, quando se calcula o coeficiente de variação, se observa que a maior variabilidade se constata para a assunção de riscos.

Quanto aos valores calculados da assimetria e curtose da base de dados completa apenas o relativo ao planejamento de atividades com orçamento detalhado (PC4) ultrapassa, em pouco 
mais de oito centésimos, o valor definido por Finney e DiStefano (2006) para a assimetria. Antes de avaliar se existe associação entre os constructos, fizeram-se os testes de normalidade de Kolmogorov-Smirnov com os escores fatoriais gerados das dimensões da orientação empreendedora, das práticas de custos e do desempenho. Devido a que todos os resultados foram significativos, indicando falta de normalidade, as relações foram aferidas com o coeficiente de correlação por postos de Spearman. O resultado obtido se exibe na Tabela 2, onde se mostram o valor do coeficiente e sua significância.

\begin{tabular}{l|l|l|l|l|l}
\hline \multicolumn{2}{c|}{ EF-PR } & EF-IN & EF-AR & EF-PC & EF-DO \\
\hline EF-PR & 1 & $\mathrm{p}<0,001$ & $\mathrm{p}<0,001$ & $\mathrm{p}<0,001$ & $\mathrm{p}<0,001$ \\
\hline EF-IN & $-0,448$ & 1 & $\mathrm{p}<0,001$ & $\mathrm{p}<0,01$ & $\mathrm{p}<0,001$ \\
\hline EF-AR & 0,335 & $-0,561$ & 1 & $\mathrm{p}<0,001$ & $\mathrm{~ns}$ \\
\hline EF-PC & 0,323 & $-0,249$ & 0,331 & 1 & $\mathrm{~ns}$ \\
\hline EF-DO & 0,445 & $-0,485$ & 0,107 & $-0,042$ & 1 \\
\hline
\end{tabular}

Tabela 2 - Coeficientes de correlação de Spearman entre os escores fatoriais (EF) da proatividade (PR), inovatividade (IN), assunção de risco (AR), prática de custos (PC) e desempenho organizacional (DO).

Confirma-se que o desempenho organizacional se correlaciona positivamente com a proatividade e de modo negativo com a inovatividade, mas a dimensão assunção de risco não mostra relação. Do mesmo modo, a prática de custos não tem correlação com o desempenho. A seguir se efetuaram as Anovas com o método de custo como preditor. Os únicos métodos assinalados pelos respondentes foram: absorção (52), variável (51) e baseado em atividade (9). Os resultados das Anovas com as dimensões da orientação empreendedora mostra que para a dimensão proatividade a comparação simultânea teve significância $(\mathrm{F}(2,109)=17,132, \mathrm{p}=$ $0,000)$. O teste pareado de Tukey para número desigual mostrou que as médias do método baseado em atividade é maior que a média de variável ( $\mathrm{p}=0,0003)$ e de absorção $(\mathrm{p}=0,0191)$. Também houve diferença entre a média de absorção e variável, sendo a primeira significativamente maior $(\mathrm{p}=0,0022)$.

Ao avaliar a dimensão inovatividade observaram-se também diferenças na comparação simultânea $(\mathrm{F}(2,109)=13,059, \mathrm{p}=0,00001)$. Entretanto, nas comparações pareadas com o teste de Tukey para número desigual a média do método variável foi significativamente maior do que a média do método de custos baseado em atividade $(\mathrm{p}=0,0009)$ e também que o de absorção $(\mathrm{p}=0,0206)$. A dimensão assunção de riscos também apresentou diferenças na comparação simultânea $(F(2,109)=35,756, p=0,00000)$. Novamente, os hotéis que utilizam o método baseado em custos são os que têm a maior média, diferenciando-se dos métodos absorção e variável. Feitas as comparações pareadas se constata que a média do que usam o método baseado em atividade são os que assumem significativamente mais riscos se contrastados aos que empregam absorção $(p=0,0001)$ e variável $(p=0,0001)$. Por sua vez, os que usam o método de absorção tem média maior aos que utilizam o método variável $(\mathrm{p}=$ 0,0369).

Para as práticas de custos não se verificaram diferenças nas comparações simultâneas na Anova usando como preditor categórico o método de custos dos hotéis. Já ao realizar a Anova com os escores fatoriais do desempenho o resultado da comparação simultânea confirma que há 
diferenças $(\mathrm{F}(2,109)=6,7729, \mathrm{p}=0,00169)$. E o teste de Tukey para número desigual comprova que as médias maiores foram daqueles hotéis que usam o método absorção e baseado em atividade, as que são estatisticamente iguais. No entanto, só a média dos que empregam absorção foi maior ao 5\% daquela calculada para os que utilizam variável $(\mathrm{p}=0,0084)$, sendo a média do baseado em atividade maior apenas com $10 \%$ de significância $(\mathrm{p}=0,0828)$.

Ao utilizar como preditor categórico o modo em que os hotéis fixam os preços, que das opções apresentadas só foram assinaladas as que se referem a fixar o valor com base no custo total (65), considerando o valor do mercado (19) e em função dos preços praticados pela concorrência (28), se constatou que não há diferença significativa nem para a orientação empreendedora nem para as práticas de custos. No entanto, ao processar os dados do desempenho se verificam diferenças na comparação simultânea $(\mathrm{F}(2,109)=6,0548, \mathrm{p}=0,00321)$. Na comparação pareada, usando o teste de Tukey para número desigual, se confirma que os hotéis que usam o valor do mercado para estabelecer os preços das diárias são os que apresentam as médias maiores do que os que se baseiam no custo total $(\mathrm{p}=0,018)$, mas igual aos que se baseia no preço praticado pela concorrência.

Nas outras duas questões relativas a custos se solicitava aos gestores que ordenassem segundo a importância atribuída pelo hotel. Uma se referia aos custos diretos, indiretos e em publicidade e propaganda. Na outra questão, se solicitava ordenar por importância quanto aos usos dos custos para a gestão. Em ambas as questões só houve dois tipos de ordenamento. Para a primeira questão as ordens foram: (1) custos diretos, indiretos e publicidade e propaganda; e, (2) custos diretos, publicidade e propaganda, e custos indiretos. Na categoria (1) se contabilizaram vinte e oito hotéis e na (2) oitenta, sendo que três questionários estavam sem resposta.

$\mathrm{Na}$ outra questão que se solicitava ordenar as respostas uma ordem foi: 1) definir preços de hospedagem; 2) admitir/demitir e qualificar pessoal; 3) decidir sobre descontos no preço de hospedagem; e, 4) tomar decisão para novos investimentos no imobilizado. Esse ordenamento foi dado por sessenta e quatro (64) estabelecimentos. Outros quarenta e seis (46) hotéis variaram apenas a ordem entre decidir sobre descontos e admitir/demitir pessoal. Para esta questão houve dois dados faltantes.

Quando se empregaram as respostas a essas duas questões de ordenar por importância como preditores categóricos nas Anovas, seja com a orientação empreendedora seja com o desempenho como variáveis dependentes, não se observou significância nas comparações feitas. Este resultado era esperado, pois as primeiras opções são coincidentes em ambas as questões para os grupos que se formaram.

\section{Considerações Finais}

Entre os temas mais estudados no âmbito da administração estratégica encontra-se o desempenho organizacional e na sua análise têm sido utilizadas diversas aproximações. Dentre elas, uma que vem ganhando importância é a orientação empreendedora que as firmas manifestam, pois se refere aos processos estratégicos que possibilitam às organizações dispor de uma base para definir sua tomada de decisões. Portanto, nos debates sobre estratégia, teoria das organizações e empreendedorismo, cada vez mais incluem na agenda que o desempenho organizacional e a sustentabilidade dos negócios são influenciados pela capacidade de empreender e inovar. A orientação empreendedora tornou-se assim um tema relevante e 
significativo para o desempenho empresarial, particularmente quando há incerteza ambiental e nos ambientes competitivos e globalizados.

Com base nos aspectos assinalados o presente estudo buscou avaliar a relação que há entre a orientação empreendedora e o desempenho organizacional, levando em consideração a gestão de custos, mensurado na hotelaria do sul do Brasil. Julgou-se importante avaliar como os métodos de custos e de precificação podem influenciar naqueles constructos.

Um primeiro achado que cabe destacar é que a relação entre a orientação empreendedora e o desempenho na amostra de hotéis participantes da pesquisa não se verifica para todas as dimensões. As análises têm demonstrado que os hotéis não se caracterizam como possuindo características empreendedoras destacadas. Ao contrário, confirma-se uma atitude conservadora, no tocante à assunção de riscos. Estes resultados empíricos são divergentes com os encontrados por Carvalho (2011), cuja pesquisa demonstra um relacionamento positivo entre a orientação empreendedora e o desempenho.

Assinala-se ainda que possuem maior orientação empreendedora os hotéis que utilizam o método de custos baseado em atividades. Paralelamente, ao trabalhar com a formação do preço da diária se constata que os hotéis que realizam a precificação baseada nos valores de mercado são os que têm melhor desempenho.

Futuros estudos da indústria da hospitalidade, incluindo outras variáveis que têm sido assinaladas como influenciando a relação entre a orientação estratégica dos hotéis e o desempenho, como por exemplo, a munificência ambiental (Carvalho, 2011), poderão trazer novas informações para o setor. Portanto se sugere dar continuidade a estes trabalhos, considerando a influência do ambiente de negócios em situações de alta e baixa temporada turística.

\section{Referências}

Babbie, E. (2003). Métodos de pesquisa de survey. Belo Horizonte: UFMG.

Beulke, R. \& Bertó, D. J. (2001). Estrutura e análise de custos. São Paulo: Saraiva.

Bortoluzzi, S. C., Ensslin, S. R. \& Ensslin, L. (2010). Avaliação de desempenho dos aspectos tangíveis e intangíveis da área de mercado: estudo de caso em uma média empresa industrial. Revista Brasileira de Gestão de Negócios, 12(37), 425-446

Bruni, A. L. \& Famá, R. (2004). Gestão de custos e formação de preços: com aplicações na calculadora HP 12C e Excel. (3a ed) São Paulo: Atlas.

Castillo, G. G. \& Quintero, J. A. J. (2013). Retos estratégicos de la indústria hotelera española del siglo XXI: horizonte 2020 em países emergentes. Tourism \& Management Studies, v. 9, n. 9(2), 13-20.

Chakravarthy, B. S. (1996). Measuring strategic performance. Strategic Management Journal, 7(5), 437-447, 1996.

Covin, J. G. \& Slevin, D. P. (1989). Strategic management of small firms in hostile and benign environments. Strategic Management Journal, 10(1), 75-87.

Covin, J. G. \& Slevin, D. P. (1991). A conceptual model of entrepreneurship as firm behavior. Entrepreneurship Theory and Practice, 16(1), 7-26.

Davenport, T. H., \& Harris, J. G. (2007). Competing on analytics: The new science of winning. Harvard Business Press. 
Dess, G. G., Lumpkin, G. T. \& Covin, J. G. (1997). Entrepreneurial strategy making and firm performance: tests of contingency and configurational models. Strategic Management Journal, 18(9), 677-695.

Fernandes, D. H. \& Santos, C. P. (2008). Orientação empreendedora: um estudo sobre as consequências do empreendedorismo nas organizações. RAE-eletrônica, 7(1), 2008.

Gunasekaran, A. \& Kobu, B. (2007). Performance measures and metrics in logistics and supply chain management: a review of recent literature (1995-2004) for research and applications. International Journal of Production Research, 45(12), 2819-2840.

Gupta, V. K., \& Dutta, D. K. (2016). Inquiring into entrepreneurial orientation: making progress, one step at a time. New England Journal of Entrepreneurship, 19(2), 1.

Hair Jr., J. F., Black, W. C., Babin, B. J., Anderson, R. E. \& Tatham R. L. (2009). Análise multivariada de dados. (6a ed), Porto Alegre: Bookman.

Halachmi, A. (2005). Performance measurement is only one way of managing performance. International journal of productivity and performance management, 54(7), 502-516.

Hansen, D. R. \& Mowen, M. M. (2001). Gestão de custos: contabilidade e controle. São Paulo: Pioneira Thomson Learning.

Harris, R. J. A primer of multivariate statistics. New York: Academic Press, 1975.

Hoque, Z. (2005). Linking environmental uncertainty to non-financial performance measures and performance: a research note. The British Accounting Review, 37, 471-481.

Hughes, M. \& Morgan, R. (2007). Deconstructing the relationship between entrepreneurial orientation and business performance at the embryonic stage of firm growth. Industrial Marketing Management, 36, 651-661.

Igarashi, D. C. C., Ensslin, S. R., Ensslin, L. \& Paladini, E. P. (2008). A qualidade do ensino sob o viés da avaliação de um programa de pós-graduação em contabilidade: proposta de estruturação de um modelo híbrido. RAUSP, 43(2), 117-137.

Koliver, O. (2009). Contabilidade de custos. Curitiba: Juruá.

Kraus, S., Halbertstadt, J., Niemand, T., Shaw, E., \& Syrja, P. (2017). Social entrepreneurship orientation: development of a measurement scale. International Journal of Entrepreneurial Behaviour and Research, 1-34.

Lacerda, F. M., Belfort, A, C., \& Martens, C. D. P. (2015). Manifestação da orientação empreendedora sem fins lucrativos. Revista de Empreendedorismo e Gestão de Pequenas Empresas, 4(2), 66-95.

Lazzarotti,F., da Silveira, A. L. T., Carvalho, C. E., Rossetto, C. R. \& Sychoski, J. C. (2015). Orientação empreendedora: um estudo das dimensões e sua relação com desempenho em empresas graduadas. $R A C, 19(6), 673-695$.

Leitão, C. R. S. \& Silva, J. D. G. (2006). Utilização do custeio variável no gerenciamento de hotéis: uma pesquisa no setor hoteleiro no nordeste brasileiro. Revista Contabilidade Vista \& Revista, 17(13), 25 - 43.

Leite, A. F. R., Lamas, S. A., \& Nóbrega, W. R. de M. (2019). Sistemas de gestão ambienta e competitividade: uma análise de múltiplos casos em meios de hospedagem de Natal - RN. Turismo: Visão e Ação, 21(1), 65-80.

Lumpkin, G. T. \& Dess, G. G. (1996). Clarifying the entrepreneurial orientation construct and linking it to performance. Academy of Management Journal, 21(1), 135-172. 
Lumpkin, G. T.\& Dess, G. G. (2001). Linking two dimensions of entrepreneurial orientation to firm performance: the moderating role of environment and industry life cycle. Journal of Business Venturing, 16(5), 429-451.

Lumpkin, G. T., Cogliser, C. C. \& Schneider, D. R. (2009). Understanding and measuring autonomy: an entrepreneurial orientation perspective. Entrepreneurship: Theory \& Practice, 33(1),47-69.

Lunkes, R. J. (2009). Informações de custos: um estudo em empresas hoteleiras na cidade de Florianópolis - SC. Turismo em Análise, 20(2), 345-367.

Martins, G. A. \& Theóphilo, C. R. (2007). Metodologia da investigação científica para ciências sociais aplicadas. São Paulo: Atlas.

Martens, C. D. P., Lacerda, F. M., Belfort, A. C., \& Freitas, H. M. R. D. (2016). Research on entrepreneurial orientation: current status and future agenda. International Journal of Entrepreneurial Behavior \& Research, 22(4), 556-583.

Melnyk, S. A., Bititci, U., Platts, K., Tobias, J., \& Andersen, B. (2014). Is performance measurement and management fit for the future? Management Accounting Research, 25(2), 173- 186.

Miller, D. (1983). The Correlates of entrepreneurship in three types of firms. Management Science, 29(7), 770-791.

Neely, A., Gregory, M. \& Platts, K. (2005). Performance measurement system design: a literature review and research agenda. International Journal of Operations \& Production Management, 25(12), 1228-1263.

Oro, I. M. \& Lavarda, C. E. F. (2017). Interação entre estratégia e desempenho organizacional: a influência da gestão familiar. Brazilian, Business Review, 14(5), 493-509.

Pelham, A. M. \& Wilson, D. T. (1996). A longitudinal study of the impact of market structure, firm structure, strategy, and market orientation culture on dimensions of small- firm performance. Journal of Academy of Marketing Science, 24(1), 27-43.

Pens, D., Amorim, B. C., Beuren E. P.; Nascimento, S. do \& Rossetto, C. R. (2019). Da crise à oportunidade: uma análise da orientação empreendedora de brasileiros nos EUA. Desenvolvimento em Questão, 17(46), 45-55.

Perez Junior, J. H., Oliveira, L. M. de \& Costa, R. G. (2005). Gestão estratégica de custos. (4a ed), São Paulo: Atlas.

Perin, M. G. \& Sampaio, C. H. (1999). Performance empresarial: uma comparação entre indicadores subjetivos e objetivos. Anais do XXIII Encontro Anual da Associação de PósGraduação e Pesquisa em Administração, Foz do Iguaçu.

Pires, P. A. da S., Ensslin, S. R., Somensi, K., \& Bornia, A. C. (2019). Transparência pública sob a perspectiva da avaliação de desempenho: revisão da literatura e proposição de pesquisas futuras. Revista de Administração, Sociedade e Inovação, 5(3), 75-97.

Rauch, A., Wiklund, J., Lumpkin, G. T. \& Frese, M. (2009). Entrepreneurial orientation and business performance: na assessment of past research and suggestions for the future. Entrepreneurship: Theory \& Practice, 33(3), 761-781.

Runyan, R., Droge, C. \& Swinney, J. (2008). Entrepreneurial orientation versus small business orientation: what are their relationships to firm performance? Journal of Small Business Management, 46(4), 567-588. 
Santos, M. \& Flores, L. C. (2017). Formação de preço dos hotéis turísticos da Cidade de São Luís/Maranhão. Rev. Bras. Pesq. Tur. São Paulo, 11(1), 133-153.

Silva, E. D da S. \& Lizote, S. A. (2019). Autoeficácia e orientação empreendedora: uma análise de suas relações em pequenas empresas de moda íntima. Revista da Micro e Pequena Empresa, 13(1), 18-103.

Tonial, G. \& Rossetto, C. R. (2018). Práticas que caracterizam a orientação empreendedora internacional: um estudo em empresas vinícolas do Sul do Brasil. Revista Ibro-Americana de Estratégia, 17(3), 128-152.

Trez, G. \& Matos, C. A. de. (2006). A influência da ordem das questões nos resultados de pesquisas surveys. Anais do Encontro Nacional dos Programas de Pós-Graduação em Administração, Salvador.

Venkatraman, N. (1989). Strategic orientation of business enterprises: the construct, dimensionality and measurement. Management Science, 35(8), 942-962.

Vergara, S. C. (1998). Projetos e relatórios de pesquisa em Administração. São Paulo: Atlas.

Viana Filho, J. R., Gomes, K. L. S. \& Souza, T. C. (2011). Custos e formação de preço como estratégia competitiva: um estudo em indústrias de suplementação animal na cidade de Rondonópolis-MT (Brasil). Anais do XII Congresso Internacional De Costos. Punta del Este, Uruguai.

Wiklund, J. \& Shepherd, D. (2005). Entrepreneurial orientation and small business performance: a configurational approach. Journal of Business Venturing, 20(1), 71-91.

Zahra, S. A. (1993). A conceptual model of entrepreneurship as firm behaviour: a critique and extension. Entrepreneurship: Theory \& Practice, 16(4), 5-21.

Zanin, A., Dal Magro,C. B. \& Mazzioni, S. (2019). Características organizacionais e a utilização da gestão de custos no processo decisório. Revista Catarinense da Ciência Contábil, 18, (nd), 1-19. 